\title{
Genotoxicity detection with special reference to micronucleation in the erythrocytes of fish species due to water pollution - A mini review
}

\author{
Soumendra Nath Talapatra*, Abantika Nandy \\ Department of Environmental Science, University of Calcutta \\ 51/1 \& 2 Hazra Road, Kolkata - 700019, India \\ *Phone: 91-33-2461-5445 \\ *E-mail address: ecologylive@yahoo.co.in
}

\begin{abstract}
Water pollution is a matter of great concern in lentic and lotic ecosystems. Generally water pollutants like heavy metals, organic compounds, etc. generate from industries and domestic activities. All of these pose serious threat to the fish population in freshwater as well as marine water bodies. An impact caused by water pollutants especially genotoxins depend not only upon its concentration, but also on the duration (acute and chronic exposure) and showed individual and/or combination of pollutants or genotoxins. Genotoxicity of fish with special reference to micronucleus induction in the erythrocytes of fish is an easy screening of water pollution. The present review deals with past and present research works of major water pollutants discharge and their impact on several fish species from available literatures.
\end{abstract}

Keywords: Water pollution; Genotoxicity; Micronucleation; Fish species; Aquatic ecosystem

\section{INTRODUCTION}

An individual and/or combinations of chemical(s) that is in the wrong place (water bodies) at the wrong concentration is either a pollutant or a contaminant, cause(s) water pollution. As a result of rapid industrial development programmes, about 50,000 chemical substances have been produced within the last decade, and recently more than 1,000 new chemicals have been introduced. (Al-Sabti, 1985). The development of industries led to increased rate of pollution in aquatic ecosystem. Several biota on earth are almost a threat due to the increased rate of organic compounds and heavy metal toxicity. Heavy metals viz. $\mathrm{Fe}$, $\mathrm{Mn}, \mathrm{Cu}, \mathrm{Zn}, \mathrm{Ni}, \mathrm{Cd}, \mathrm{Pb}, \mathrm{Cr}, \mathrm{Hg}$ etc. and aromatic hydrocarbons viz. naphthalene, anthracene, phenanthrene, fluoranthene, pyrene, triphenylene, chrizene, perylene, 3-4-benzoapyrene, pesticides etc. are a few of them, which cause an enhanced frequency of chromosomal aberrations both in floral as well as in faunal world. The aquatic environment is the ultimate destination for discharge of almost all industrial wastewater.

Water quality can be determined through biological assessment with special reference to genotoxicity detection in conjunction with chemical and physical analysis. In genotoxicity detection, micronucleus (MN) test in the fish erythrocytes is a suitable measure. 
Genotoxicity describes the property of chemical agents that damages the genetic information within a cell causing mutations, which may have direct or indirect effects on the DNA. Aquatic ecosystem is a better area to monitor genotoxicity of inorganic as well as organic compounds, since these pollutants (genotoxicants/genotoxins) that contaminate the air and soil, reach the aquatic environment ultimately and accumulate easily there. It is well known that the disposal of pollutants into aquatic ecosystems can lead to their accumulation both in sediments and the benthic and pelagic food chains (including fish). About the genotoxicity of an investigated body of water, the fish species chosen for chromosomal aberration studies should be easy to handle and inexpensive, require limited amounts of space and equipment, be sensitive, and have a suitable karyotype consisting of a small number of large chromosomes.

The chromosomes aberration led to micronucleus induction in the cell(s). Generally, $\mathrm{MN}$ is formed by the condensation of whole chromosomes or fragmented chromosomes that are not incorporated into the main nucleus during mitosis, due to clastogenic or aneugenic effects (Al-Sabti and Metcalfe, 1995).

Fish are excellent test model for the study of the mutagenic and/or carcinogenic potential of contaminants present in water bodies since they can metabolize, concentrate and store waterborne pollutants (Al-Sabti, 1991). Genotoxic effect in fish is a matter of great concern because of their potential effects on human health after consumption. Since fish often respond to toxicants in a similar way to higher vertebrates, they can be used to screen for chemicals that are potentially mutagenic, carcinogenic and teratogenic in humans. Fish are very important in the daily diets of the local population (Power, 1989). In genotoxicity assessment, the detection of micronucleus (MN) in fish help us to know the status of water quality as well as the health of particular species and potential risk, it might have after consumption.

The study of micronucleus induction in fish by various chemical(s) have already been reported earlier internationally (Hooftman and De Raat, 1982; Carrasco et al., 1990; De Flora et al., 1993; Al-Sabti and Metcalfe, 1995; Ayllon and Garcia-Vazquez, 2000; Grisolia and Corderio, 2000; Grisolia and Starling, 2001; Cavas and Ergene-Gozukara, 2003; Ferraro et al., 2004). The MN test in fish erythrocytes have also been reported at national level by many researchers (Manna and Sadhukhan, 1986; Talapatra et al. 2006; Talapatra and Banerjee, 2007, Talapatra et al., 2007; Yadav and Trivedi, 2009; Talapatra et al. 2010; Talapatra et al. 2014).

The present review aims to compile different available literatures on genotoxicity assessment with special reference to micronucleus induction in the erythrocytes of fish species due to water pollution.

\section{INDUCTION OF MICRONUCLEATION IN FISH ERYTHROCYTES BY INORGANIC AND ORGANIC WATER POLLUTANTS}

Micronuclei are small, intracytoplasmic masses of chromatin resulting from chromosome breaks after clastogenic action or whole chromosomes that do not migrate during anaphase as a result of aneugenic effect (Manna and Sadhukhan, 1986; Heddle et al., 1991; Al-Sabti and Metcalfe, 1995; Ferraro et al., 2004).

The efficacy of this test system as an indicator of structural genomic damage has already been proven and the MN test has been successfully used as a measure of genotoxic stress in fish by heavy metals and oraganics, under both laboratory and field conditions. 


\section{1. Heavy metals and organic compounds in water cause genotoxicity in fish}

The study of various literatures clearly reveal that genotoxicity experiment especially induction of micronucleus in the erythrocytes of fish is a suitable indicator of in situ as well as ex situ exposure of chemical contaminants present in water.

The micronucleus test in fish has potential for detecting clastogenic and aneugenic substances in water bodies. Since teleost erythrocytes are nucleated, micronuclei have been scored as a measure of genotoxicity (Talapatra et al., 2014).

Different studies have been documented that the peripheral erythrocytes have a high incidence of micronucleus after exposure to different toxicants both under field and laboratory condition. During micronucleus study intraspecific factors may affect the response in assays include age (Christine and Costa, 1983), sex (Urlando and Heddle, 1990) and diet (Virgano et al., 1993).

It was also reported by many workers that flyash contains various genotoxins such as nickel, copper, aluminium, benzene, PCBs, polycyclic aromatics etc. (Belpaeme et al. 1997; Dharmlata, 2002) rather than individual heavy metals and organic compound or combinations. According to Portoa et al. (2005), genotoxic effect by using the micronucleus test (MNT) of some organic compounds in fish species was evaluated.

Sanchez-Galan et al. (1998) have scored micronucleus number in kidney erythrocytes of wild Brown trout, Salmo trutta, caught in different fluvial ecosystems characterized by different levels of anthropic influence. According to them, brown trout samples from rivers with high anthropic influence possess significantly higher frequencies of micronuclei than fish sampled from less anthropic influenced river.

The study of micronuclei frequencies in two different ecosystems such as fresh water and marine in different fish species such as fresh water (Carassius sp. and Zacco platypus) and for marine (Leiognathus nuchalis and Dictrema tennincki). It was detected that micronucleus induction in gill cells are more than hematopoetic cells by clastogenic/aneugenic agents. Micronucleus induction was also season dependent due to concentration of genotoxins higher in summer in river water (Hayashi et al. 1998).

Campana et al. (1999) have studied the genotoxicity of pyrethroid lambda cyhalothrin in aquatic ecosystem using the micronucleus test in erythrocytes of Cheirodon interruptus interruptus. According to them pyrethroid has potent genotoxic effects in this fish and MNT is a suitable measure.

Ayllon and Garcia-vazquez (2000) have compared the sensitivity of European minnow (Phoxinus phoxinus) and mollie (Poecilia latipinna) to toxic heavy metals ( $\mathrm{Cd}$ and $\mathrm{Hg}$ ) using micronucleus test in renal erythrocytes of these fishes. They concluded that mollie is sensitive to both metals whereas minnow is not sensitive to $\mathrm{Hg}$.

Al-Sabti et al. (2000) has used micronucleus induction in fish erythrocytes to study the genotoxicity of chlorotriazine Reactive Azo Red 120 textile dye in aquatic ecosystems. According to them this genotoxic dye increases micronucleus in a dose and time-dependent way.

Grisolia and Starling (2001) have compared the sensitivity of Tilapia rendalli, Oreochromis niloticus and Cyprinus carpio to clastogens present in the effluent of two municipal sewage treatment plant by using micronucleus test.

The result showed that $T$. rendalli was the most sensitive species to both clastogens and C. carpio was the most resistant species. By using colchicine, mitomycin, cyclophosphamide, acrylamide, methyl-methane sulphonate and N-ethyl-N-nitrosourea on Oncorhynchus mykiss, it was investigated by Ayllon and Garcia-vazquez (2001) that the above mentioned 
compounds are genotoxic and cause induction of micronucleus in renal erythrocytes of the fish.

From the study of the genotoxic effects of an industrial pollutant on erythrocytes of an inter-tidal fish species, Pholis gunnellus (butter fish) by using micronucleus test, it was concluded by Bombail et al (2001) that frequencies of micronuclei and are higher in the inner zone of Firth with high industrial contamination than that of the outer zone which is comparatively clear.

Ateeq et al. (2002) have investigated the effects of 2,4-dichlorophenoxyacetic acid and butachlor on the erythrocytes of catfish species Clarius batrachus. They showed that the herbicides used in this experiments are genotoxic and cause micronuclei induction in erythrocytes of the fish.

Abul Farah et al. (2003) have compared the genotoxicity of pentachlorophenol (PCP) and 2,4-dichlorophenoxyacetic acid (2,4-D) by using fresh water air-breathing fish Channa punctatus. They showed micronucleated erythrocytes in fish treated with above compounds. According to them PCP is more toxic than 2,4-D in terms of MN induction. In the other investigation, the genotoxic effect of a textile mill effluent on erythrocytes and gill cells of Oreochromis niloticus using micronucleus test by Cavas and Ergene-Gozukara (2003). It was indicated that a dose-dependent increase was observed in the frequencies of micronucleus in gill cells as well as erythrocytes of the fish. Rodriguez-Cea et al. (2003) showed the comparison of the sensitivity of genotoxins such as colchicines, cyclophosphamide and cadmium in fish, brown trout (Salmo trutta), european eel (Anguilla anguilla) and european minnow (Phoxinus phoxinus) and it was reported that brown trouts are more sensitive than minnows and eels to these three chemical compounds.

Buschini et al. (2004) have noticed the micronucleus induction in fish by the effects of disinfectants for potabolization of lake water. In this study they have observed that Cyprinus carpio sampled from lake water treated with sodium hypochlorite and chloride dioxide shown frequency of micronucleus in the circulating erythrocytes of this fish.

Porto et al. (2005) have evaluated genotoxic effects of mercury $(\mathrm{Hg})$ on three tropically distinct characin fish species collected from two riverine environments in the Amazon basin, the modeirais a polluted area and the salimos is an unpolluted area. In this study they have observed micronuclei frequencies in Prochilodus migricans (detritivore), Mylossoma duriventris (omnivore) and Hoplius malabaricus (piscivore).

The result clearly revealed that the mean frequencies of micronuclei were higher in fish species collected from modeira than that of salimoes river. It was reported by the other researchers that the genotoxic effects of effluents from a petroleum refinery and a chromium processing plant were evaluated in Oreochromis niloticus (perciformes) using the micronucleus test, which considered as genetic damage indicators, were also evaluated on erythrocytes (Cavas et al. 2005).

Bolognesia et al. (2006) reported assessment of micronuclei induction in peripheral erythrocytes of fish exposed to xenobiotics under controlled conditions. The standardization and to assessment was done of the predictive value of the cytogenetic analysis by MN test in fish erythrocytes as a biomarker for marine environmental contamination.

$\mathrm{MN}$ frequency baseline in erythrocytes was evaluated in a number of fish species from a reference area namely S. Teresa, La Spezia Gulf and genotoxic potential of a number of common chemical contaminants and mixtures was determined in fish experimentally exposed in aquarium under controlled conditions.

Talapatra and Banerjee (2007) have reported the genotoxic effect by studying the micronucleus test to detection of presence or absence of genotoxins in water. In this study, 
micronuclei frequencies were scored in the gill and kidney erythrocytes of the fish Labeo bata grown in the sewage-fed fish farms of East Calcutta wetlands and observed potent genotoxic effect by heavy metals and other organics when mixed with sewage water.

Assessment of biological marker at genetic level in fish Labeo bata and Oreochromis mossambica inhabited in the pond located at industrial vicinity of thermal power plant, micronucleus test in the peripheral and renal erythrocytes is a suitable measure, in which the presence or absence of genotoxins can be detected in water. Researchers have observed induction of micronucleus in both the erythrocytes and bata is more sensitive than tilapia when inhabited in flyash containing pond water (Talapatra et al., 2007).

Hoshinaa et al. (2008) have reported micronucleus tests were performed on erythrocytes of Oreochromis niloticus (perciformes, cichlidae) in order to evaluate the water quality of the Atibaia river, in an area that receives effluents discharge of a petroleum refinery and also to evaluate the effectiveness of the treatments used by the refinery.

Yadab and Trivedi (2009) have reported sublethal exposure of heavy metals induces micronuclei in fish, Channa punctata. Significant increase over and above negative control in the frequency of micronuclei was observed in fishes exposed to heavy metal compounds.

Talapatra et al. (2010) reported that metronidazole (MTZ), a nitroimidazole drug, is primarily used as an anti-protozoan or an anti-bacterial drug in human, although its genotoxic and carcinogenic effects have been widely reported, particularly in aquatic organisms (). MTZ has induced micronuclei in the erythrocytes when exposed to the fish, Channa punctatus in laboratory condition.

Muranli and Güner (2011) have reported the induction of micronuclei (MN) in erythrocytes of mosquito fish (Gambusia affinis). Fish were exposed to three different concentrations of lambda-cyhalothrin (LCT) $\left(1 \times 10^{-4} \mu \mathrm{g} / 1,2 \times 10^{-4} \mu \mathrm{g} / 1,4 \times 10^{-4}\right.$ $\mu \mathrm{g} / \mathrm{l})$ for periods of $6,12,24$, and $48 \mathrm{~h}$. The $\mathrm{MN}$ and the ratio of polychromatic erythrocytes (PCEs) to normochromatic erythrocytes (NCEs) were evaluated to assess genotoxicity and cytotoxicity. The pesticide LCT has induced MN in erythrocytes of $G$. affinis. The PCE/NCE ratio was also decreased after 24- and 48-h treatments of $4 \times 10^{-4}$ $\mu \mathrm{g} / 1 \mathrm{LCT}$. According to them, the LCT has genotoxic and cytotoxic potential on G. affinis.

Buker et al. (2012) have studied the genotoxicity and putative mutagenic effects of benzene (BZN) in the erythrocytes of the electric fish Apteronotus bonapartii (gymnotiformes, apteronotidae) using the micronucleus test (MN), under controlled laboratory conditions.

Electric fsh were collected in the Solimões River, Manaus-AM, Brazil, and the specimens were exposed to 10 and $25 \mathrm{ppm}$ concentrations of BZN, in $150 \mathrm{~L}$ tanks. Blood samples were collected at 0 (T0), 24, 48, 72 and 96 hours of exposure. For the concentration of $10 \mathrm{ppm}$ BZN, no increased induction of MN frequencies but in $25 \mathrm{ppm}$ of BZN the MN rates presented a signifcant increase after 72 hours, which indicated a time-dependent effect, especially at the highest BZN concentrations tested. This investigation reinforces the potential use of the endemic South American electric fish as a suitable genotoxicity biological model for biomonitoring purposes in the Amazon.

Fuzinatto et al. (2013) have reported by assessing the frequency of micronucleated (MN) erythrocytes of the fish species, Oreochromis niloticus, from the Cubatão do Sul River.

This river is the source of drinking water for the region of Florianópolis, capital of Santa Catarina State, Brazil. Based on the observation of elevated MN erythrocytes frequency in $O$. niloticus exposed to water samples from along the river course. They have concluded that the complex environmental mixtures of water from the Cubatão do Sul river have genotoxic potential in the said fish. According to them, the genotoxicity most likely 
originated from agricultural runoff and domestic effluents released without treatment, based on the evidence from literature data and a survey in the region.

Talapatra et al. (2014) have studied and scored the frequencies of micronucleated erythrocytes in peripheral blood of catfish, Heteropneustes fossilis (bloch) after acute in-vivo exposure of zinc at different concentrations in the laboratory condition. Erythrocytes of exposed fishes compared to control groups of fishes and confirmed that dose- and timedependent micronucleation in the peripheral erythrocytes of fish after short-term exposure to zinc could provide valuable information regarding zinc containing effluent quality and also help in genetic biomonitoring with this test model.

\section{DISCUSSION AND CONCLUSION}

The published results presented here clearly reveal that water pollution causes genotoxicity with special reference to micronucleus induction by inorganic elements (heavy metals) and organic chemicals at acute exposure. From the previous research works in international as well as national level, the study of micronucleus induction in fish by various chemical(s) have already been reported earlier by many researchers (Hooftman and De Raat, 1982; Manna and Sadhukhan, 1986; Carrasco et al., 1990; De Flora et al., 1993; Al-Sabti and Metcalfe, 1995; Ayllon and Garcia-Vazquez, 2000; Grisolia and Corderio, 2000; Grisolia and Starling, 2001; Cavas and Ergene-Gozukara, 2003; Ferraro et al., 2004; Talapatra et al. 2006; Talapatra and Banerjee, 2007, Talapatra et al., 2007; Yadav and Trivedi, 2009; Talapatra et al., 2010; Talapatra et al., 2014).

In genotoxicity, micronucleated erythrocytes are the suitable indicator for detecting health status of fish. The frequencies of micronuclei were induced in fish when exposed to inorganic or organic chemical agents in in-situ as well as laboratory condition (Al-Sabti and Metcalfe, 1995; Minissi et al., 1996; Ayllon and Garcia-Vazquez, 2000; Cavas and ErgeneGozukara, 2003; Cavas et al., 2005; Talapatra et al., 2014). Genotoxicity study with special reference to micronucleus test in fish erythrocytes by different industrial pollutants have been investigated and bioindicators could be identified easily (Carrasco et al., 1990; Bombail et al., 2001; Cavas and Ergene-Gozukara, 2003; Talapatra and Banerjee, 2007; Talapatra et al., 2014, Pravin U. Singare et al., 2014).

In the present review, it was concluded that genotoxiicty study with special reference to micronucleus induction in the erythrocytes of fish is an easy tool for the detection of water pollution load in aquatic bodies by industrial, agricultural and domestic wastewater discharge. This present review will also help for further research in different fish species exposed to water pollutants because of compilation of selected literatures authors have presented here.

\section{Acknowledgement}

The authors convey their gratitude to the Department of Environmental Science, University of Calcutta, for providing the necessary facilities for doing this study. 


\section{References}

[1] Abul Farah M., Ateeq M., Ali M.N., Ahmad W., Ecotoxicol Environ Saf 54 (2003) 25-29.

[2] Al-Sabti K., Handbook of Genotoxic Effects and Fish Chromosomes, J. Stefan Institute Publisher, 1991, pp. 221, ISBN 8680023175.

[3] Al-Sabti K., J Fish Biol 26 (1985) 13-19.

[4] Al-Sabti K., Metcalfe C.D., Mutat Res 343 (1995) 121-135.

[5] Al-Sabti K. Ecotoxicol Environ Saf 47 (2000) 149-155.

[6] Ateeq B., Abul Farah M., Niyamat Ali M., Ahmad W., Mutat Res 518 (2002) 135-144.

[7] Ayllon F., Garcia-Vazquez E., Mutat Res 467 (2000) 177-186.

[8] Barsiene J., Genetics and Evolution of Aquatic Organisms, A. R. Beaumont (Ed.), Great Britain, Cambridge University Press, 1995, 102.

[9] Belpaeme K., Cooreman K., Kirsh-volders M., Mutat Res 379 (1997) s130.

[10] Bolognesia C., Perronea E., Roggieria P., Pampaninb D.M., Sciuttoa A., Aquatic Toxicology 78 (2006) S93-S98.

[11] Bombail V., Aw D., Gordon E., Batty J., Chemosphere 44 (2001) 283-392.

[12] Buker A., Carvalhol M.S., Conceicao M.B., Alves-Gomes J.A., J Braz Soc Ecotoxicol 7(1) (2012) 65-73.

[13] Buschini A., Martino A., Gustavino B., Monfrinotti M., Poli P., Rossi C., Santaro M., Porr A. J. M., Rizzoni M., Mutat Res 557 (2004) 119-129.

[14] Campana M. A., Panzeri A. M., Moreno M. J., Doulot F. N., Mutat Res 438 (1999) 155-161.

[15] Carrasco K.R., Tillbury L.K., Myers M.S., Fish Aquat Sci 47 (1990) 2123-2136.

[16] Cavas T., Ergene-Gozukara S., Mutat Res 538 (2003) 81-91.

[17] Cavas T., Garanko N.N., Arkhipchuk V.V., Food Chem Toxicol 43 (2005) 569-574.

[18] Chattopadhyay B., Chatterjee A., Mukhopadhyay S.K., Aquat Ecosys Health Manage 5(2) (2002) 191-203.

[19] Christine N.T., Costa M., Biol Trac Elemnt Res 5 (1983) 55-71.

[20] De Flora S., Vigano S.L., D’Agostini F., Camoirano A., Baagnosco M., Bennicelli C., Melodia F., Arillo A., Mutat Res 319 (1993) 167-177.

[21] Dharmlata J. N., Himalayan J Env Zoo 16 (2002) 87-90.

[22] Fenech M., Crott J., Turner J., Brown S., Mutagenesis 14 (1999) 605-612.

[23] Ferraro M. V. M., Fenocchio A. S., Mantovani M. S., deO. Ribeiro C., Cestari M. M., Gen Mol Biol 27 (2004) 103-107.

[24] Fuzinatto C.F., Flohr L., Melegari S.P., Matias W.G., Ecotoxicology and Environmental Safety 98 ( 2013) 103-109.

[25] Grisolia C.K., Corderio C.M.T., Gen Mol Biol 23 (2000) 235-239. 
[26] Grisolia C.K., Starling F.L.R.M., Mutat Res 491 (2001) 39-44.

[27] Heddle J. A., Cimino M. C., Hayashi M., Romagna F., Shelby M. D., Tucker J. D., Vanparys Ph., MacGregor J. J., Environ Mol Mutagen 18 (1991) 227-291.

[28] Hooftman R.N., De Raat W.K., Mutat. Res. 104 (1982) 147-152.

[29] Hoshinaa M.M., Angelisb D.F., Marin-Moralesa M.A., Genetic Toxicol Environ Mutagen 656 (2008) 44-48.

[30] Jha N.A., Hutchinson T.H., Mackay J.M., Elliot B.M., Dixons D.R., Mutat. Res. 391 (1997) 179-188.

[31] Kirsh-Volders M., Fenech M., Mutagenesis 16 (2001) 51-58.

[32] Maltby E., Waterlogged wealth. An Earthscan Paperback, International Institute of Environment and Development, 1986, 200.

[33] Manna G.K., Sadhukhan A., Curr Sci 55 (1986) 498-501.

[34] Muranli, F.D.G., Güner, U., Mutat Res 726 (2011) 104-108.

[35] Murakawa M., Jung S-K., Iijima K., Yonehara S., Cell Death Differen 8 (2001) 298-307.

[36] Pachecco M., Santos M.A., Ecotoxicol Environ Saf 40 (1998) 71-83.

[37] Palhares D., Grisolia C.K., Genet Mol Biol 25 (2002) 281-284.

[38] Pfeiffer P., Goedecke W. Obe G., Mutagenesis 15 (4) (1999) 289-302.

[39] Portoa J.I.R., Araujob C.S.O., Feldberga E., Environ Res 97 (2005) 287-292.

[40] Power D.A., Science 246 (1989) 352-358.

[41] Rodriguez-Cea A., Ayllon F., Garcia-vazquez E., Ecotoxicol Environ Saf 56 (2003) 442-448.

[42] Talapatra S. N., Environmental Science (Eds. A. Mukhopadhyay and S. Ghosh). 2006, 207-211.

[43] Talapatra S.N., Banerjee S.K., Food Chem Toxicol 45 (2007) 210-215.

[44] Talapatra S.N., Ganguly P., Mukhopadhyay A., Banerjee S. K., Asian J Wat Environ Polln 4(1) (2007) 139-144.

[45] Talapatra S.N, Banerjee P., Mukhopadhyay A., International Letters of Natural Sciences 4 (2014) 36-43.

[46] Talapatra S.N., Dasgupta S., Guha G., Auddy M., Mukhopadhyay A., Food Chem Toxicol 48 (2010) 3458-3461.

[47] Urlando C., Heddle J. A., Mutat Res 234 (1990) 199-204.

[48] Virgano L. A., Bagnasco M., Bennicelli C., Melodia F., Comp Biochem Physiol 104 (1993) 51-55.

[49] Yadav K.K, Trivedi S.P., Chemosphere 77 (2009) 1495-1500.

[50] Zhang L., Rothman N., Wang Y., Hayes R.B., Li G., Dosemeci M., Yin S., Kolachana P., Titenko-Holland N., Smith M.T., Carcinogenesis 19 (1998) 1955-1961. 
[51] Pravin U. Singare, M. V. A. Ansari, N. N. Dixit, International Letters of Natural Sciences 10 (2014) 69-78.

[52] Pravin U. Singare, M. V. A. Ansari, N. N. Dixit, International Letters of Natural Sciences 10 (2014) 79-88.

[53] Pravin U. Singare, M. V. A. Ansari, N. N. Dixit, International Letters of Natural Sciences 11(1) (2014) 44-53.

[54] Pravin U. Singare, M. V. A. Ansari, N. N. Dixit, International Letters of Natural Sciences 11(1) (2014) 54-61. 